\title{
Late Post-Traumatic Cerebrospinal Rhinorrhoea
}

\section{Fulbert Kouakou, Romuald Kouitcheu, Alban Slim Mbende, Dominique N’Dri Oka*, Guy Varlet}

Neurosurgery Unit, Yopougon Teaching Hospital, Abidjan, Ivory Coast

Email:^ndriokad@gmail.com

How to cite this paper: Kouakou, F., Kouitcheu, R., Mbende, A.S., Oka, D.N. and Varlet, G. (2017) Late Post-Traumatic Cerebrospinal Rhinorrhoea. Open Journal of Modern Neurosurgery, 7, 103-111. https://doi.org/10.4236/ojmn.2017.73011

Received: March 28, 2017

Accepted: July 21, 2017

Published: July 24, 2017

Copyright $\odot 2017$ by authors and Scientific Research Publishing Inc. This work is licensed under the Creative Commons Attribution International License (CC BY 4.0).

http://creativecommons.org/licenses/by/4.0/

(c) (i) Open Access

\begin{abstract}
Cerebrospinal fluid (CSF) rhinorrhoea results from anatomical breach between the subarachnoid space and air sinus cavities of the skull base and traumatic CSF rhinorrhoea accounts for $80 \%-90 \%$ of all cases of CSF leaks. We sought to report the case of a 16-year-old patient with a history of head injury following a fall from a tree, who developed a post-traumatic CSF rhinorrhoea after an onset of meningitis. The patient sustained a fall from a 6-meter tree in 2008, and was reviewed by our neurosurgical team in February 2016 for a 1-month history of progressive headaches associated with fever, asthenia and left CSF rhinorrhoea. Clinical examination revealed frank meningism and abundant CSF leak from the left nostril. CT scanning showed fractures of the left frontal bone and sinus wall associated with a massive pneumocephalus. The patient benefited from surgical repair of the tear and post-operative lumbar punctures at day 15. The patient's guardian was informed that non-identifiable information from the case would be submitted for publication and he provided consent.
\end{abstract}

\section{Keywords}

Post-Traumatic Cerebrospinal Rhinorrhoea, Meningitis, Surgical Repair

\section{Introduction}

Cerebrospinal fluid (CSF) rhinorrhoea results from anatomical breach between the subarachnoid space and air sinus cavities of the skull base [1]. CSF rhinorrhoea can be classified into two groups: traumatic and non-traumatic; and traumatic CSF rhinorrhoea are either accidental or iatrogenic [2]. Traumatic CSF rhinorrhoea accounts for $80 \%-90 \%$ of all cases of CSF leaks [2]. The vast majority of CSF leaks heals in 7 - 10 days with conservative treatment; and lumbar drainage is warranted if this fails [3] [4]. But many surgeons prefer surgical repair in these patients. The percentage of failure after surgical repair is estimated 
to be around $6 \%-32 \%$ [4]. The risk of meningitis persists as long as the leak is active. We sought to report the case of a 16-year-old patient with a history of head injury following a fall from a tree, who developed a post-traumatic CSF rhinorrhoea after an onset of meningitis.

\section{Observation}

We report the case of a 16-year-old patient with a history of head trauma and initial loss of consciousness following a fall of a 6-meter tree in 2008. He was reviewed by our neurosurgical team in February 2016 for a 1-month history of progressive headache associated with fever, asthenia and left CSF rhinorrhoea.

Clinical examination revealed an average general state, a $38.5^{\circ} \mathrm{C}$ fever, a 75 pulsations/min pulse, an alert but slow patient, meningism with positive KERNIZ and BRUDZINSKI signs, absent sensory-motor and cranial nerves deficit and abundant left CSF rhinorrhoea (see Video 1). Head NECT and ECT scans showed massive pneumocephalus of the left frontal lobe communicating with the frontal sinus and ipsilateral air cells, the frontal horns of lateral ventricles and the 4 th ventricle, of the basal cisterns and hyper dense meninges (Figure 1). The patient received pneumococcal vaccination.

Surgical repair of the anterior cranialfossa was achieved through a sub-frontal approach. After frontal craniotomy a large dural tear was seen communicating with the frontal pneumocephalus and the left interventricular foramen (Figure 2). We performed a dural plasty using the galea then we obstructed the left nasofrontal canal with temporal muscle, bone wax and surgicell. The immediate post-operative follow-up was uneventful and there was no CSF leak (see Video 2). Fifteen days later, a recurrent left CSF rhinorrhoea was discovered and the patient benefited with subtractive lumbar puncture. CSF analysis showed an inflammatory response without germs. We warranted an empiric antibiotherapy with ceftriaxone and metronidazole.

Post-operative head NECT and ECT scans showed an unequivocal clearance of the pneumocephalus (Figure 3 ). The patient was asymptomatic at 8-month follow-up.

\section{Discussion}

The relationship between skull base fractures and the CSF rhinorrhoea is well described in the literature. Identification of the type of skull base fractures is important and dictates the appropriate treatment. Anterior fossa skull base fractures

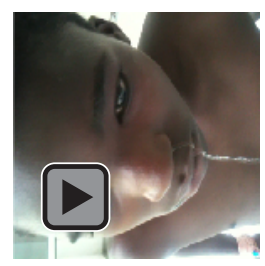

Video 1. Preoperative video showing an abundant left CSF rhinorrhoea. 


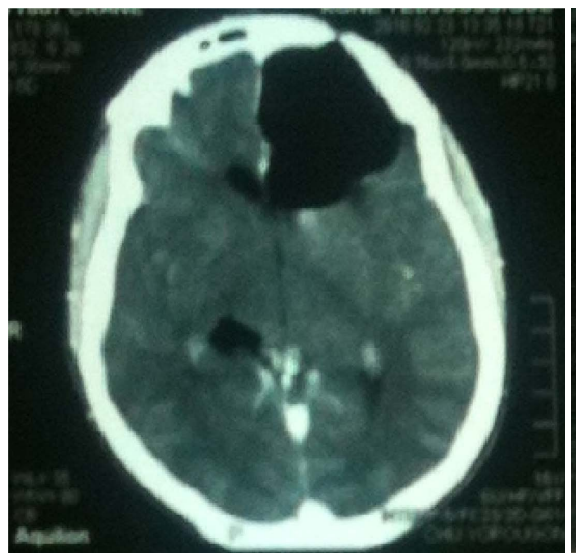

(a)

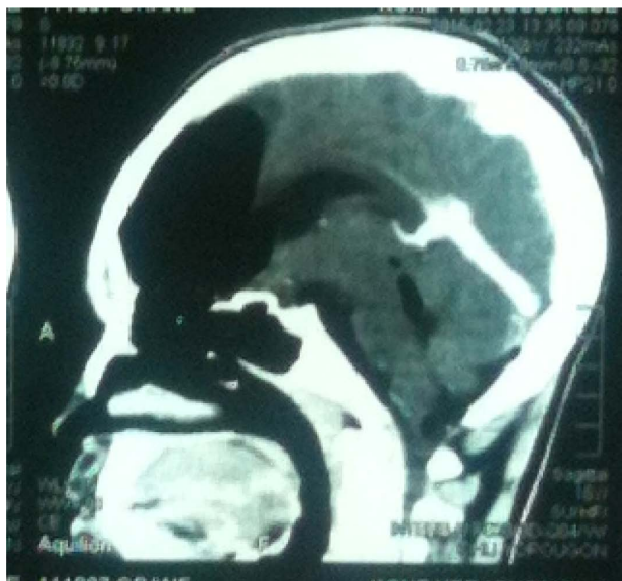

(c)

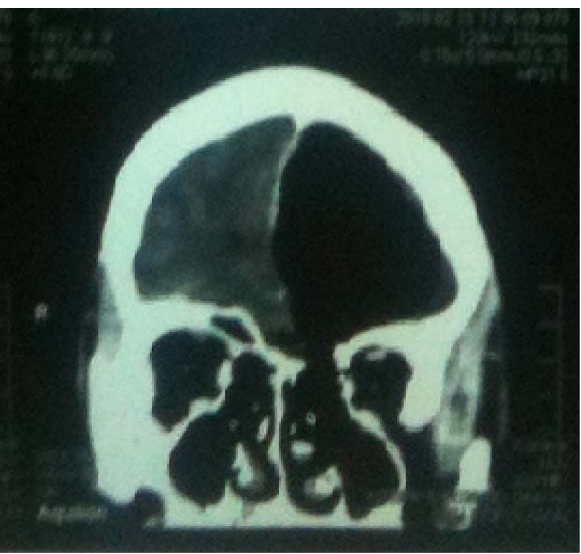

(b)

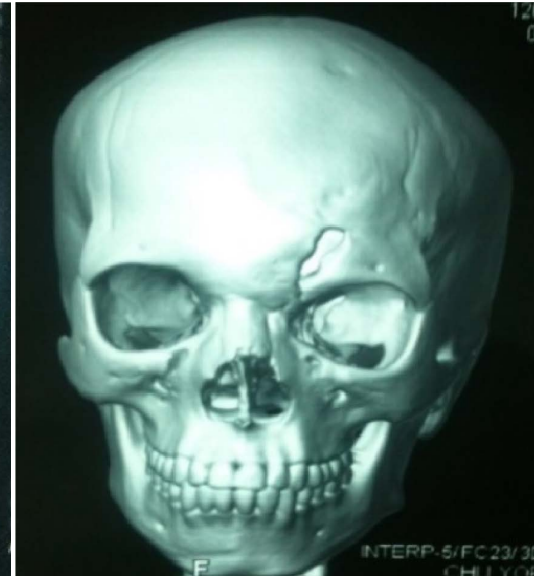

(d)

Figure 1. Axial CT (a), coronal (b), sagittal (c) and 3D reconstruction (d) images showed a left frontal air porencephalic cavity (measuring $51 \mathrm{~mm}+41 \mathrm{~mm}$ ) communicating the frontal sinus and the ipsilateral air cells; pneumocephalus in the lateral ventricles frontal horns, 4th ventricle, basal cisterns and a meningeal contrast enhancement, a fracture of the anterior and posterior walls of the left frontal sinus.

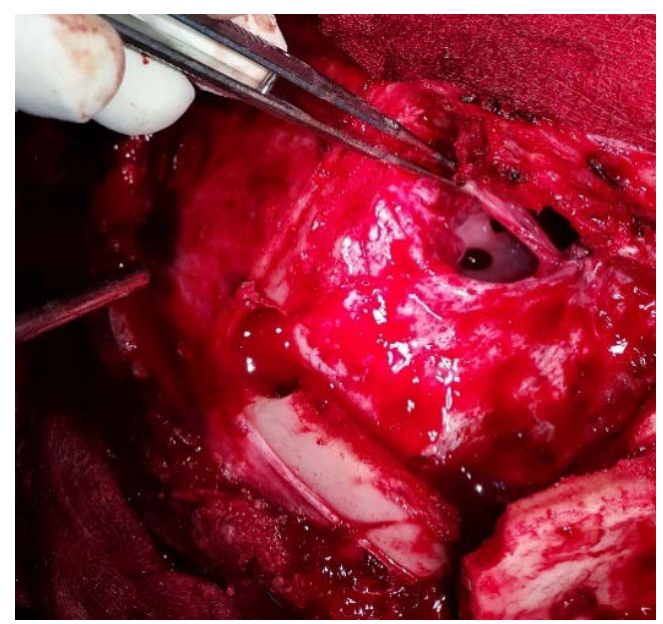

Figure 2. Intraoperative view showing a large dural breach and a large frontal porencephalic cavity and a left ventricular. 


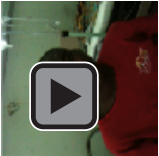

Video 2. J10 postoperative image showing absence of left CSF rhinorrhoea.

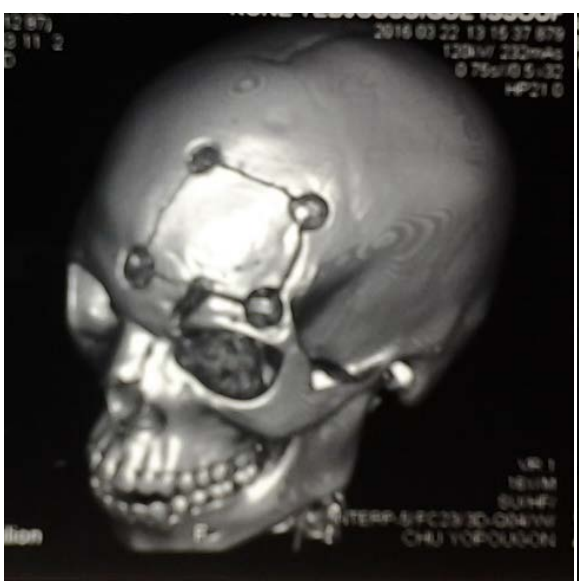

(a)

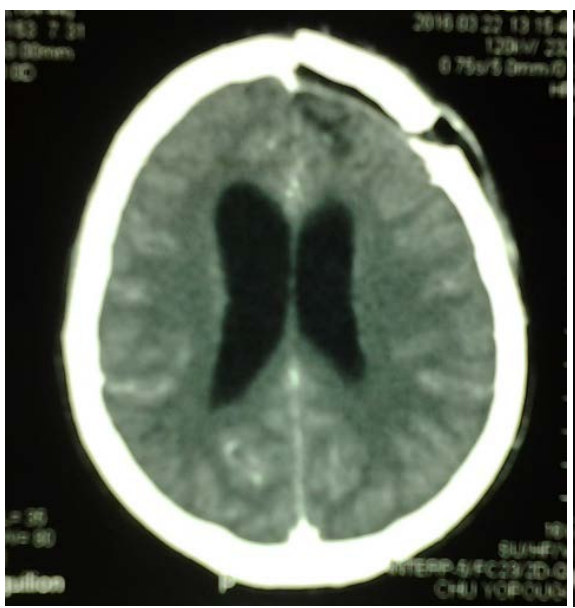

(c)

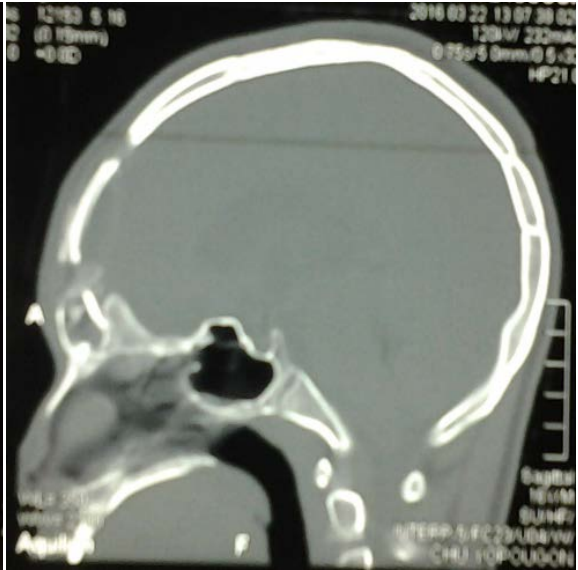

(b)

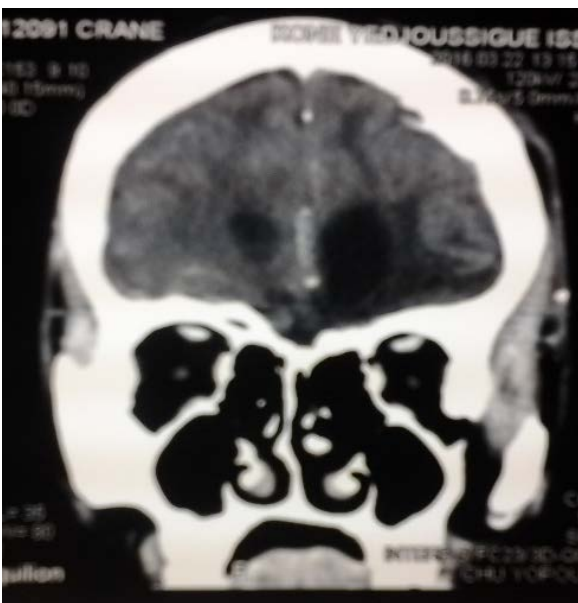

(d)

Figure 3. Postoperative axial CT (c) and coronal (d), bone window (b) and 3D reconstruction (a) with and without contrast injection show almost complete resorption of pneumocephalus.

are responsible for the vast majority of CSF rhinorrhoea [5]. According to Friedman et al. around $84 \%$ of CSF fistulas result skull base fractures involving the frontal sinus, followed by the orbit and the petrous bone [6]. Although anterior fossa skull base fractures are responsible for the vast majority of CSF rhinorrhoea, Brodie et al. reported cases of CSF rhinorrhoea following temporal bone fractures [7]. In their series of 820 cases of temporal bone fractures, they found that $72 \%$ of patients with CSF fistulas had CSF rhinorrhoea. In our case, the patient had fractured frontal bone and frontal sinus walls. The optimal management of post-traumatic CSF rhinorrhoea should emphasize the selection of an appropriate treatment strategy [2]. Around $70 \%$ of post-traumatic fistulas generally resolve spontaneously within 7 days without surgery. First-line treatment 
consists of bed rest in a horizontal position, stopping straining activities, the use of laxatives and a lumbar drain can be put in place for 7 days. Some surgeons might use a lumbar drain postoperatively. When post-traumatic fistulas fail to resolve spontaneously within 7 - 10 days, there is an increased risk of developing cerebrospinal meningitis.

Several surgical techniques have been described in the literature, ranging from conventional frontal craniotomy, which can be unilateral or bilateral, to the far lateral supra-sinus trans-frontal approach [8]. Endoscopictrans-nasal approach has become the standard procedure for the repair of most of these fistulas [9]. Endoscopic repair is indicated in those patients where CSF leak has failed to resolve with conservative measures [10]. In our case, we performed a left unilateral frontal craniotomy. The issue of whether or not to use a lumbar drain after CSF rhinorrhoea repair remains controversial in the literature. Indications of lumbar drainage are unclear, and most surgeons rely on their past anecdotal findings [8]. Some authors found no statistical difference between using a lumbar drain or not after surgical repair of CSF rhinorrhoea [11]. Our patient benefited from a lumbar drain 15 days post-operatively. The risk of recurrent CSF leak after transcranial repair of posttraumatic CSF rhinorrhoea has been reported at around $6 \%-32 \%$ [4]. The risk of cerebrospinal meningitis persists as long as CSF leak is active. In their series of 111 patients with CSF rhinorrhoea, Daudia et al. reported three cases of meningitis following surgical repair. Brodie et al. reported one case of post-operative meningitis in their meta-analysis of $324 \mathrm{CSF}$ leak [7]. In our case, the occurrence of CSF rhinorrhoea 15 days after surgery was successfully managed with a lumbar drain. Post-traumatic cerebrospinal rhinorrhoea remains a serious challenge for neurosurgeons especially due to the timing of surgical repair. The overall rate of meningitis prior to surgery is reported between $10 \%$ and $37 \%$ [12]. The risk of postoperative meningitis varies between $0.3 \%$ and $7 \%$ [13] [14] [15].

Prophylactic antibiotics are often used during CSF leak and the aim is to reduce the risk of meningitis or local infection before or after surgical repair. This strategy however beneficial in some instances, carries a huge risk of selecting resistant bacteria, which can potentially lead to meningitis. As a result, the routine use of prophylactic antibiotics in CSF leak has been since questioned. Eftekhar et al. [12] conducted a randomized study where 109 patients with traumatic pneumocephalus were selected and a sample group received a 5-day prophylactic ceftriaxone and another control group received no antibiotic. They showed that the overall rate of meningitis was not significantly different (18.9\% with antibiotics, $21.5 \%$ without antibiotics, $\mathrm{p}=0.74$ ). Four meta-analyses showed contradictory results. In 1997 a meta-analysis conducted by Brodie [16] involving 324 patients with cranial base fractures found a lower rate of meningitis associated with the use of prophylactic antibiotics. But, 3 larger meta-analysis have all shown the opposite. Rathore [17] in 1991 ( $\mathrm{n}=848)$, Villalobos et al. [18] in 1998 ( $\mathrm{n}=1241)$, and Ratilal et al. [19] in $2011(\mathrm{n}=2376)$ found that antibiotic prophylaxis had no impact on the rate of meningitis. 
Lumbar drains are sometimes used in order to minimize increased intracranial pressure in the course of the immediate postoperative period that could cause displacement of the skull base repair. The placement of a catheter in the intrathecal space has significant risks, including meningitis, persistent leakage of CSF at the site of dural puncture, pneumocephalus, hernia of the brain and death. A review of the literature identified 19 studies that met the inclusion criteria relevant for the use of lumbar drainage after endoscopic CSF leak repair. Many of these studies reported success rates ranging from 83\% to 94\% [14] [20]. Some authors concluded fairly that lumbar drains are necessary complements to achieving these success rates. On the other hand, some studies indicate otherwise. In a meta-analysis of 289 cases of CSF fistulas, Hegazy et al. [13] reported a $90 \%$ success rate at the first surgical repair, but did not find a statistically significant difference when a lumbar drain was used or not. Similarly, in a randomized controlled trial, Albu et al. [21] found a success rate of $92 \%$ to $95 \%$ of endoscopic repair and did not see any association between this success and the use of lumbar drain $(p=0.2)$. A series of additional cases had similar results despite the etiology of the fistula [22] or the size of the dural defect, but [23] there was a difference in the length of hospital stay. This difference was reported in both conservatively managed patients with or without lumbar drain and those with or without a lumbar drain after endoscopic repair [20] [24] [25].

Literature review of 5 studies which discussed the use of bone grafts in the management of CSF leaks, found success rates of between $89 \%$ and $100 \%$ for the first repair [26] [27] and 98\% for the second repair [26]. In their series of 55 patients, Germani et al. [28] evaluated combinations of various repair materials and found that bone repair had a success rate of $83 \%$. In a previous study conducted by Kong et al. [29] tight closure using fascia overlay with iliac bone yielded superior results of closure for a high flow of CSF leak compared with fat transplant. As with fat transplants, bone grafts appear to be a good option for repair.

The main advantage of using allografts or xenografts in CSF leak repair is to save the patient from the morbidity of a donor site. For this to be a valid option, successful repair using allografts must match that of autografts. A review of the literature identified 5 studies concerning allografts or xenografts use. One was a meta-analysis and 4 were case series. Interpretation of these data appeared unreliable because of the small number of cases and the different variables used. Germani et al. [28] conducted a study where 30 patients underwent CSF leak repair using acellular human dermis with or without additional layers. The success rate in the allograft group was $97 \%$ compared with $92 \%$ in the non-allograft group. In Lorenz et al. [30] study, septal cartilage was used between the allografted acellular dermal layers and a free mucosa grafted as a superposition, whilst Eloy et al. [31] used a nasoseptal flap as the final layer. Similarly, Illing et al. [32] used small mucosal grafts of porcine intestine in 155 patients with a nasoseptal flap. All these techniques showed high success rates.

Glues and sealants, fibrin glues, and related additions are commonly used in 
the endoscopic repair of the base of the skull in an effort to maximize the stability of the graft and seal the leak. They contribute to a successful but uncertain repair. Following a review of the literature, a case control study was identified in which patients with CSF leaks were repaired with a pedicled nasoseptal flap with or without the use of a dural sealant. The authors did not find any significant difference in the recurrence of the leak between the two groups [33]. In vitro $(\mathrm{N}=$ 2) studies comparing various endoscopic repair strategies found that the burst pressure was significantly increased when a fibrin sealant was used than in the control group [34]. In a randomized animal study, [14] leaks were repaired with or without fibrin glue, and then the pericranial graft adhesion was later assessed. The fibrin glue group had significantly better graft adherence [35]. Further human studies are needed to clarify the contribution of sealants in endoscopic CSF leakage repair [36] [37].

\section{Conclusion}

This report supports the view that the best management of CSF leaks is based primarily on surgeon preference, taking into account both cost and morbidity. It also supports that antibiotics and lumbar drains may not be useful. This assessment lacks unfortunately, strong evidence and we rely heavily on future top level research to help guide the repair of CSF leaks.

\section{References}

[1] Giannetti, A.V., de Morais Silva Santiago, A.P., Becker, H.M.G. and Guimaraes, R.E.S. (2011) Comparative Study between Primary Spontaneous Cerebrospinal Fluid Fistula and Late Traumatic Fistula. Otolaryngology_Head and Neck Surgery, 144, 463-468. https://doi.org/10.1177/0194599810391729

[2] Abuabara, A. (2007) Cerebrospinal Fluid Rhinorrhoea: Diagnosis and Management. Medicina Oral, Patología Oral y Cirugía Bucal, 12, E397-E400.

[3] Kerr, J.T., Chu, F.W. and Bayles, S.W. (2005) Cerebrospinal Fluid Rhinorrhea: Diagnosis and Management. Otolaryngologic Clinics of North America, 38, 597-611. https://doi.org/10.1016/j.otc.2005.03.011

[4] Bell, R.B., Dierks, E.J., Homer, L. and Potter, B.E. (2004) Management of Cerebrospinal Fluid Leak Associated with Craniomaxillofacial Trauma. Journal of Oral and Maxillofacial Surgery, 62, 676-684. https://doi.org/10.1016/j.joms.2003.08.032

[5] Scholsem, M., Scholtes, F., Collignon, F., Robe, P., Dubuisson, A., Kaschten, B., et al. (2008) Surgical Management of Anterior Cranial Base Fractures with Cerebrospinal Fluid Fistulae: A Single-Institution Experience. Neurosurgery, 62, 463-471. https://doi.org/10.1227/01.neu.0000316014.97926.82

[6] Friedman, J.A., Ebersold, M.J. and Quast, L.M. (2001) Post-Traumatic Cerebrospinal Fluid Leakage. World Journal of Surgery, 25, 1062-1066.

https://doi.org/10.1007/s00268-001-0059-7

[7] Brodie, H.A. and Thompson, T.C. (1997) Management of Complications from 820 Temporal Bone Fractures. American Journal of Otolaryngology, 18, 188-197.

[8] Casiano, R.R. and Jassir, D. (1999) Endoscopic Cerebrospinal Fluid Rhinorrhea Repair: Is a Lumbar Drain Necessary? Otolaryngology-Head and Neck Surgery, 121, 745-750. https://doi.org/10.1053/hn.1999.v121.a98754 
[9] Tóth, M., Selivanova, O., Schaefer, S. and Mann, W. (2010) Spontaneous Cerebrospinal Fluid Rhinorrhea: A Clinical and Anatomical Study. The Laryngoscope, 120, 1724-1729. https://doi.org/10.1002/lary.20993

[10] Bolger, W.E. and McLaughlin, K. (2003) Cranial Bone Grafts in Encephalocele Repair: A Preliminary Report. American Journal of Rhinology, 17, 153-158.

[11] Meco, C., Arrer, E. and Oberascher, G. (2007) Efficacy of Cerebrospinal Fluid Fistula Repair: Sensitive Quality Control Using the Beta-Trace Protein Test. American Journal of Rhinology, 21, 729-736. https://doi.org/10.2500/ajr.2007.21.3105

[12] Eftekhar, B., Ghodsi, M., Nejat, F., Ketabchi, E. and Esmaeeli, B. (2004) Prophylactic Administration of Ceftriaxone for the Prevention of Meningitis after Traumatic Pneumocephalus: Results of a Clinical Trial. Journal of Neurosurgery, 101, 757-761. https://doi.org/10.3171/jns.2004.101.5.0757

[13] Hegazy, H.M., Carrau, R.L., Snyderman, C.H. and Zweig, J. (2000) Transnasal Endoscopic Repair of Cerebrospinal Fluid Rhinorrhea: A Meta-Analysis. Laryngoscope, 110, 1166-1172. https://doi.org/10.1097/00005537-200007000-00019

[14] Lee, T.J., Huang, C.C., Chuang, C.C. and Huang, S.F. (2004) Transnasal Endoscopic Repair of Cerebrospinal Fluid Rhinorrhea and Skull Base Defect: Ten-Year Experience. Laryngoscope, 114, 1475-1481. https://doi.org/10.1097/00005537-200408000-00029

[15] Carrau, R.L., Snyderman, C., Janecka, I.P., Sekhar, L., Sen, C. and D’Amico, F. (1991) Antibiotic Prophylaxis in Cranial Base Surgery. Head Neck, 13, 311-317. https://doi.org/10.1002/hed.2880130407

[16] Brodie, H.A. (1997) Prophylactic Antibiotics for Posttraumatic Cerebrospinal Fluid Fistulae. A Meta-Analysis. Archives of Otolaryngology_Head \& Neck Surgery, 123, 749-752. https://doi.org/10.1001/archotol.1997.01900070093016

[17] Rathore, M.H. (1991) Do Prophylactic Antibiotics Prevent Meningitis after Basilar Skull Fracture? The Pediatric Infectious Disease Journal, 10, 87-88. https://doi.org/10.1097/00006454-199102000-00001

[18] Villalobos, T., Arango, C., Kubilis, P. and Rathore, M. (1998) Antibiotic Prophylaxis after Basilar Skull Fractures: A Meta-Analysis. Clinical Infectious Diseases, 27, 364 369. https://doi.org/10.1086/514666

[19] Ratilal, B.O., Costa, J., Sampaio, C. and Pappamikail, L. (2011) Antibiotic Prophylaxis for Preventing Meningitis in Patients with Basilar Skull Fractures. The Cochrane Database of Systematic Reviews, No. 8, CD004884. https://doi.org/10.1002/14651858.cd004884.pub3

[20] White, D.R., Dubin, M.G. and Senior, B.A. (2003) Endoscopic Repair of Cerebrospinal Fluid Leaks after Neurosurgical Procedures. American Journal of Otolaryngology, 24, 213-216.

[21] Albu, S., Emanuelli, E., Trombitas, V. and Florian, I.S. (2013) Effectiveness of Lumbar Drains on Recurrence Rates in Endoscopic Surgery of Cerebrospinal Fluid Leaks. The American Journal of Rhinology \& Allergy, 27, e190-e194. https://doi.org/10.2500/ajra.2013.27.3986

[22] Caballero, N., Bhalla, V., Stankiewicz, J.A. and Welch, K.C. (2012) Effect of Lumbar Drain Placement on Recurrence of Cerebrospinal Rhinorrhea after Endoscopic Repair. International Forum of Allergy \& Rhinology, 2, 222-226. https://doi.org/10.1002/alr.21023

[23] Hughes, R.G.M., Jones, N.S. and Robertson, I.J.A. (1997) The Endoscopic Treatment of Cerebrospinal Fluid Rhinorrhoea: The Nottingham Experience. The Journal of Laryngology \& Otology, 111, 125-128. 
[24] Yeo, N.K., Cho, G.S., Kim, C.J., et al. (2013) The Effectiveness of Lumbar Drainage in the Conservative and Surgical Treatment of Traumatic Cerebrospinal Fluid Rhinorrhea. Acta Otorrinolaringologica, 133, 82-90.

https://doi.org/10.3109/00016489.2012.717180

[25] Zuckerman, J.D. and DelGaudio, J.M. (2008) Utility of Preoperative High-Resolution CT and Intra-Operative Image Guidance in Identification of Cerebrospinal Fluid Leaks for Endoscopic Repair. American Journal of Rhinology, 22, 151-154. https://doi.org/10.2500/ajr.2008.22.3150

[26] Presutti, L., Mattioli, F., Villari, D., Marchioni, D. and Alicandri-Ciufelli, M. (2009) Transnasal Endoscopic Treatment of Cerebrospinal Fluid Leak: 17 Years' Experience. ACTA Otorhinolaryngologica Italica, 29, 191-196.

[27] Bolger, W.E. (2005) Endoscopic Transpterygoid Approach to the Lateral Sphenoid Recess: Surgical Approach and Clinical Experience. Otolaryngology-Head and Neck Surgery, 133, 20-26.

[28] Germani, R.M., Vivero, R., Herzallah, I.R. and Casiano, R.R. (2007) Endoscopic Reconstruction of Large Anterior Skull Base Defects Using Acellular Dermal Allograft. American Journal of Rhinology, 21, 615-618. https://doi.org/10.2500/ajr.2007.21.3080

[29] Kong, D.S., Kim, H.Y., et al. (2011) Challenging Reconstructive Techniques for Skull Base Defect Following Endoscopic Endonasal Approaches. Acta Neurochirurgica, 153, 807-813. https://doi.org/10.1007/s00701-011-0941-5

[30] Lorenz, R.R., Dean, R.L., Hurley, D.B., Chuang, J. and Citardi, M.J. (2003) Endoscopic Reconstruction of Anterior and Middle Cranial Fossa Defects Using Acellular Dermal Allograft. Laryngoscope, 113, 496-501. https://doi.org/10.1097/00005537-200303000-00019

[31] Eloy, J.A., Patel, S.K., Shukla, P.A., Smith, M.L., Choudhry, O.J. and Liu, J.K. (2013) Triple-Layer Reconstruction Technique for Large Cribriform Defects after Endoscopic Endonasal Resection of Anterior Skull Base Tumors. International Forum of Allergy \& Rhinology, 3, 204-211. https://doi.org/10.1002/alr.21089

[32] Illing, E., Chaaban, M.R., Riley, K.O. and Woodworth, B.A. (2013) Porcine Small Intestine Submucosal Graft for Endoscopic Skull Base Reconstruction. International Forum of Allergy \& Rhinology, 3, 928-932. https://doi.org/10.1002/alr.21206

[33] Eloy, J.A., Choudhry, O.J., Friedel, M.E., Kuperan, A.B. and Liu, J.K. (2012) Endoscopic Nasoseptal Flap Repair of Skull Base Defects: Is Addition of a Dural Sealant Necessary? Otolaryngology-Head and Neck Surgery, 147, 161-166. https://doi.org/10.1177/0194599812437530

[34] Fandino, M., Macdonald, K., Singh, D., Whyne, C. and Witterick, I. (2013) Determining the Best Graft-Sealant Combination for Skull Base Repair Using a Soft Tissue in Vitro Porcine Model. International Forum of Allergy \& Rhinology, 3, 212 216. https://doi.org/10.1002/alr.21085

[35] De Almeida, J.R., Ghotme, K., Leong, I., Drake, J., James, A.L. and Witterick, I.J. (2009) A New Porcine Skull Base Model: Fibrin Glue Improves Strength of Cerebrospinal Fluid Leak Repairs. Otolaryngology-Head and Neck Surgery, 141, 184189.

[36] Alexander, A., Mathew, J., Varghese, A.M. and Ganesan, S. (2016) Endoscopic Repair of CSF Fistulae: A Ten Year Experience. Journal of Clinical and Diagnostic Research, 10, MC01-4. https://doi.org/10.7860/JCDR/2016/18903.8390

[37] Mishra, S.K., Mathew, G.A., Paul, R.R., Asif, S.K., John, M., Varghese, A.M. and Kurien, M. (2016) Endoscopic Repair of CSF Rhinorrhea: An Institutional Experience. Iranian Journal of Otorhinolaryngology, 28, 39-43. 
Submit or recommend next manuscript to SCIRP and we will provide best service for you:

Accepting pre-submission inquiries through Email, Facebook, LinkedIn, Twitter, etc. A wide selection of journals (inclusive of 9 subjects, more than 200 journals)

Providing 24-hour high-quality service

User-friendly online submission system

Fair and swift peer-review system

Efficient typesetting and proofreading procedure

Display of the result of downloads and visits, as well as the number of cited articles Maximum dissemination of your research work

Submit your manuscript at: http://papersubmission.scirp.org/

Or contact ojmn@scirp.org 